\title{
Editorial
}

\section{Original Articles Featured in I-Ways Journal}

This is the inaugural issue of I-Ways to publish original articles by policy-makers, regulators, advisors as well as academics from all parts of the world. the main themes to be focused on are (1) national and municipal case studies describing strategies and policies, regulations as well as examples of innovative applications, especially citizen-centric services; (2) initiatives by intergovernmental organizations, such as the World Bank, OECD, ITU, EU, ADB as well as NGOs; (3) key policy-regulatory issues including reform in governance as with greater transparency and citizen participation, new telecom regulatory and trade initiatives, e-Identity projects, cybersecurity and privacy, publicprivate partnerships, and rural development; and (4) advances in ICT technologies as the Internet, mobile services, payments, broadband, etc.

Several items in this issue provide details on developments in national ICT strategies and policies in particular Indonesia and new initiatives in East Africa. Mobile Government is to be increasingly focused upon because the increase in mobile phones around the world exceeds 4 billion and this wireless medium is rapidly becoming the main facilitator of voice and messages across the world. The results of meetings of major international organizations also are featured in I-Ways. OECD's recent ministerial in Seoul, Korea that focused on the Internet received extensive coverage. In this issue two of the key topics in the Asia-Pacific Economic Cooperation (APEC) forum held in November in Lima, Peru. These are initiatives are for the 16 members (1) to establish a regional economic integration agreement (free trade area) and (2) and place higher priority on e-Governance as the solution to improving government efficiency and transparency. A review of a cardinal issue in the privacy protection and access to government records debate for many years is presented in an article "Access to Information 25 Years On."

Russell Pipe, Editor 